\title{
Do CAP direct payments stabilise farm income? Empirical evidences from a constant sample of Italian farms
}

\author{
S. Severini ${ }^{*}$, A. Tantari and G. Di Tommaso
}

*Correspondence: severini@unitus.it Università della Tuscia-DAFNE, Via S. C. De Lellis, snc., 01100 Viterbo, Italy

\begin{abstract}
Common Agricultural Policy uses a large share of its budget to support and stabilise the income of EU farmers by means of direct payments (DP). This paper assesses how much and how DP reduce the variability of farm income over time.

The analysis is developed on a constant sample of 2402 Italian farms during the decade 2003-2012. It considers both the whole sample and farms grouped according to: types of farming; economic size classes; relative importance of DP. Income variability is analysed by mean of variance decomposition by income components.

Variability of farm income over time is high and most of it is coming from the revenue component. The DP stabilise farm income and this is mainly because DP are less variable than the remaining part of income. Indeed, DP are found to play a very limited countercyclical role against fluctuations of the remaining part of farm income. Finally, DP are not targeted to those farms facing the highest level of income variability. These latter two results suggest that, while DP stabilise farm income, there is a potentially large room of manoeuvre for increasing the efficiency of DP as income stabilising tool.

Keywords: Farm income, Farm management, Common agricultural policy, Variance decomposition, Direct payments

JEL classification: Q12, Q18, G320
\end{abstract}

\section{Springer}

\section{Background}

A large share of the support provided to EU farmers by the Common Agricultural Policy (CAP) is delivered by means of Direct Payments (DP). These are aimed at increasing and stabilising farm income as well as supporting farmers to deliver a multiplicity of goods and services.

Stabilising income is an important problem faced by farmers so that there has been a growing attention to cope with it. However, even if it has been claimed that DP play an income stabilising role, empirical evidences on this issue are scant.

The analysis focuses on the role of DP in stabilising farm income in a large constant sample of Italian farms considering the period 2003-2012. The first objective of the analysis is to estimate the extent of farm income variability over time at farm level. This is important also to assess whether the recent introduction within the CAP of measures aimed at supporting farmers to manage risk is justified. Second, the analysis identifies the income components that most contribute to income variability focusing on the farm

(C) 2016 Severini et al. Open Access This article is distributed under the terms of the Creative Commons Attribution 4.0 International License (http://creativecommons.org/licenses/by/4.0/), which permits unrestricted use, distribution, and reproduction in any medium provided you give appropriate credit to the original author(s) and the source, provide a link to the Creative Commons license, and indicate if changes were made. 
revenues, DP and costs for external (i.e. not own by the family) factors. Third, the analysis is aimed at assessing whether DP reduce farm income variability. Empirical results support the hypothesis that DP stabilise farm income even if noticeable differences exist among farm groups. This aspect is used to discuss whether the new structure of DP introduced by the recent reform is expected to address income stabilisation goals better than the previous policy. Finally, the analysis explores how DP play such income stabilising role. Particular attention is paid to evaluate if DP have a countercyclical effect against fluctuations of market income (i.e. farm income net of DP) over time and if DP are targeted towards those farms facing the highest level of variability of market income. These latter two aspects are perceived as relevant in order to better design DP policies in the future to make more effective measures to stabilise farm income.

The following section briefly describes DP policies, reviews the literature on farm income stabilisation and the role played by CAP in this regards, and describes the contribution of this analysis to the current literature and policy debate. The third section presents data and methodology used in the empirical analysis. The fourth section presents the main results of such analysis. The last section discusses the results and provides some policy considerations that can be derived from them.

\section{Background: EU direct payment policy and farm income stabilisation}

Most of the support provided to EU farmers by the Common Agricultural Policy (CAP) is delivered by means of Direct Payments (DP) that account for around $77 \%$ of the Producer Subsidy Estimate provided by CAP (OECD 2014). According to the European Commission (2010a), DP accounted for around $27 \%$ of the agricultural income of EU farms and, therefore, are very important to ensure farm profitability but also contribute to maintain rural population and the provision of public goods.

Stabilising farm income is perceived as an important problem faced by farmers (Meuwissen et al. 2008; OECD 2009). Farming is a risky business because forces (such as weather) beyond the control of farmers affect their income (Mishra and Sandretto 2002). Indeed, variability of farm income far exceeds the variability of the income experienced by non-farm households (Mishra et al. 2002). This is one of the main reasons why farm income stability has been one of the goals of agricultural policies both in the US and EU because income instability affects farmers' well-being and decisions, their ability to expand operations and repay debt and, in turns, this can also have secondary effects on agribusiness firms and creditors (Mishra and Sandretto 2002; Vrolijk and Poppe 2008). Despite this, there are not many analysis specifically focused on the stability of the whole farm income even if "... farmers are ultimately concerned more about their net incomes than about prices and costs" (Mishra and Sandretto 2002, p. 219).

To assess the level of instability farmers are facing, it is preferred to work on farmlevel time-series because at higher levels of aggregation, poor income in some farms are offset by good income in others. Thus, aggregated data can severely underestimate farm level risk (Kimura et al. 2010; OECD 2009).

Unfortunately, there are limited empirical evidences on this subject in the EU. Vrolijk and Poppe (2008) analysed a very large samples of farms based on several EU countries. This allows for comparison among countries and types of farming supporting the idea that farm income variability is generally high and that differences among countries and types of farms exist: more specialised and small farms are often faced with relatively 
higher income variability. Agrosynergie (2011) found that variability appears on average high in specialist granivore and specialist field crops farms, while low in mixed farms. Furthermore, variability is higher in small than in large farms in most types of farming and across regions (Agrosynergie 2011).

DP have been claimed to play an income stabilising role (OECD 2009; Cafiero et al. 2007) and the limited empirical evidences support this hypothesis (Agrosynergie 2011; El Benni et al. 2012; Enjolras et al. 2014). Italian farms use management tools (Direct payments, crop insurance and inputs) to improve their income and reduce its volatility (Enjolras et al. 2014). Agrosynergie (2011) founds that the relevance of such stabilising effect increases with the relative importance of DP but this is not always the case because of the many differences among types of farming. Indeed, it has not been explored in details how DP play such stabilising role. Three aspects are worth further investigation.

The first is to assess whether DP are less variable than the other income components. Indeed, the empirical analysis has shown that the amount of DP does also vary over time at individual farm level because of several reasons. Because some DP are coupled to production, DP vary yearly according to production choices. Payment entitlements own by a farmer generate DP only if he/she declares an equivalent number of eligible hectares; thus, changes in land availability can push the amount of eligible land below the amount of own entitlements reducing the overall amount of DP received. DP are reduced in those years in which farmers are found not fulfilling conditionality requirements. Farmers may receive part of the expected DP in the following year because of administrative or legal problems that delay the payment. Finally, the level of DP changes when a policy reform is introduced.

The second aspect to consider is whether DP play a countercyclical role against fluctuations of the remaining part of the income. This is because the variability of DP over time could indeed reduce the variability of the overall income in the peculiar case in which DP increase in those years in which the remaining part of the income declines because, for example, drops in production levels or product prices.

Third, because in Italy the SPS historical model generated a not homogeneous distribution of DP even among farms of the same region, DP may be relatively more abundant in farms with high income variability or not. In the first case, it is possible to say that the targeting efficiency of DP as income stabilising policy is high.

\section{Methods}

The analysis has been developed on the individual farms belonging to the whole Italian sample of the EU Farm Accounting Data Network (FADN) farms during all years of the period 2003-2012. ${ }^{1}$

As the main goal of the analysis is to assess the variability of farm economic results over time, there is the need to select farms that have been in the samples for a reasonably large number of years. The analysis considers a constant sample of 2402 farms for 10 years. The use of a constant sample allows for better comparing results among farm groups and sub-periods (Enjolras et al. 2014). On the contrary, in an unbalanced panel dataset, farms refers to time series of different length and to different periods (e.g. at the beginning or at the end of the considered interval of time) making results sensitive to changes in the composition of the sample of farms over time. 
Unfortunately, the use of a constant panel implies to work with a sub-sample of the whole FADN sample that, because of this, cannot be considered strictly representative of the whole farm population. However, the comparison of the distributions of farms both within the whole sample and within the considered sub-sample shows that the latter does not provide an incomplete representation of the Italian farming sector. In fact, the distribution of the farms within the sub-sample is very similar to the distribution of farms within the whole sample in terms of several dimensions (Tables 6 and 7 in Appendix). The Finger and Kreinin (1979) similarity indexes computed on the two samples show a level of similarity that is never below $90 \%{ }^{2}$

All data has been deflated by means of the GDP deflator allowing comparison over time. While trends may still be present in deflated series, it has been decided to not de-trend these because of the following reasons. First, estimating the presence of a trend over short series (10 years, in the considered case) can be misleading because a single data can strongly affect the estimation. Furthermore, improvements of agricultural technologies leading to relevant trends are expected to happen over a long period of time (El Benni and Finger 2013). Second, using detrended data in the variance decomposition analysis has been shown to lead to biased results (Offutt and Blandford 1986). Third, trend analysis performed on the considered data has shown that deflating allowed to eliminate most of the trends present in the data. Indeed, significant (i.e. with $\mathrm{R}^{2}>0.6$ ) linear trends in deflated farm income exist in only $11 \%$ of the considered farms. Furthermore, in these few farms, trends are negative in $28 \%$ of the cases but positive in the others (Table 8 in the Appendix). Finally, results suggest that none of the types of farming are clearly more affected by trends than other types of farming, because farms with significant FI trends are more or less distributed equally among all types of farming.

The analysis considers both the whole sample and the farms grouped according to: a) 7 Types of farming; b) Economic size classes (Small, medium and large); c) relative importance of DP (No DP and 4 quartiles) (Table 1). Data regarding each of these groups can be analysed given that a sufficient number of farms are represented within each group.

The focus is on Farm Income (FI) that is defined as:

$$
\mathrm{FI}=\mathrm{REV}-\mathrm{EC}+\mathrm{DP}=\mathrm{MI}+\mathrm{DP}
$$

where REV is revenues, EC is costs for external (i.e. non-family owned) factors, MI is market income (i.e. FI-DP). Thus, FI represents the remuneration to fixed factors of production of the family (work, land and capital) and remuneration to the entrepreneur's risks (loss/profit) in the accounting year (European Commission 2010b).

The relative importance of DP is assessed by means of two indicators:

$$
\mathrm{PSE}=\mathrm{DP} /(\mathrm{REV}+\mathrm{DP})
$$

that is the relative importance of DP over the whole farm receipts (REV + DP);

$$
\mathrm{DP} / \mathrm{FI}
$$

that is the share of DP on farm income.

Variability of farm income is assessed by calculating variance and Coefficient of Variation (CV) over the 10 year period in each individual farm.

The role of the three components of (1) on income variability is assessed by applying the variance decomposition by income sources that relies on multiplicative or 
Table 1 Sample size ad relative importance of direct payments

\begin{tabular}{|c|c|c|c|c|}
\hline & & \multirow{3}{*}{$\begin{array}{l}\text { Sample size } \\
\text { number }\end{array}$} & \multicolumn{2}{|c|}{ Importance of DP: } \\
\hline & & & PSE & $\mathrm{DP} / \mathrm{Fl}$ \\
\hline & & & Mean & Mean \\
\hline Types of farming (TF) ${ }^{c}$ : & TF & & & \\
\hline Specialist field crops & 1 & 571 & $22.9 \%$ & $80.9 \%$ \\
\hline Specialist horticulture & 2 & 276 & $0.8 \%$ & $2.0 \%$ \\
\hline Specialist permanent crops & 3 & 715 & $8.3 \% \mathrm{~b}$ & $25.5 \%$ a \\
\hline Specialist grazing livestock & 4 & 492 & $16.3 \%$ a & $45.5 \% \mathrm{~b}$ \\
\hline Specialist granivore & 5 & 84 & $5.7 \% b$ & $18.6 \%$ a \\
\hline Mixed cropping & 6 & 161 & $13.6 \%$ a & $44.7 \% b$ \\
\hline Mixed livestock and mixed crops-livestock & 7 & 103 & $17.6 \%$ a & $60.6 \%$ \\
\hline \multicolumn{5}{|l|}{ Economic size $(E S U)^{c}$ : } \\
\hline Small (Classes 1, 2, 3) & & 697 & $14.6 \%$ & $56.1 \%$ \\
\hline Medium (Classes 4, 5, 6) & & 1595 & $12.9 \%$ & $37.5 \% \mathrm{a}$ \\
\hline Large (Classes 7, 8) & & 110 & $9.3 \%$ & $31.1 \% \mathrm{a}$ \\
\hline \multicolumn{5}{|l|}{ PSE level: } \\
\hline No DP & 0 & 247 & $0.0 \%$ & $0.0 \%$ \\
\hline Low & $1 \mathrm{st}$ & 540 & $2.0 \%$ & $6.5 \%$ \\
\hline Low-medium & 2nd & 539 & $8.1 \%$ & $27.6 \%$ \\
\hline Medium-high & $3 r d$ & 537 & $16.4 \%$ & $55.6 \%$ \\
\hline High & 4th & 539 & $32.4 \%$ & $100.4 \%$ \\
\hline Total sample & & 2402 & $13.2 \%$ & $42.6 \%$ \\
\hline
\end{tabular}

Mean values of PSE (DP/(REV + DP)) and DP/FI in the considered groups and the whole sample of farms Source: Own elaborations on a constant sample of the whole Italian FADN farms, years 2003-2012

'Differences between groups statistically significant at $5 \%$ according to Scheffe's test

additive identities (Burt and Finley 1968; Hadrich 2013; El Benni and Finger 2013; Mishra et al. 2002).

In the first case, variance decomposition can be expressed for the product of two random variables (e.g. crop production as the product of yield and acreage) by mean of a Taylor's series expansion in the following way $\left(y=x_{1} \cdot x_{2}\right)$ :

$$
\begin{aligned}
\operatorname{Var}(y) & =\mu_{2}^{2} \operatorname{Var}\left(x_{1}\right)+\mu_{1}^{2} \operatorname{Var}\left(x_{2}\right)+2 \mu_{1} \mu_{2} \operatorname{Cov}\left(x_{1}, x_{2}\right)+E\left[\left(x_{1}-\mu_{1}\right)\left(x_{2}-\mu_{2}\right)-\operatorname{Cov}\left(x_{1}, x_{2}\right)\right]^{2} \\
& +2 \mu_{1} E\left(x_{1}-\mu_{1}\right)\left(x_{2}-\mu_{2}\right)^{2}+2 \mu_{2} E\left(x_{1}-\mu_{1}\right)^{2}\left(x_{2}-\mu_{2}\right)
\end{aligned}
$$

where $\mu_{1}$ and $\mu_{2}$ denote the means of $x_{1}$ and $x_{2}$.

The first two terms are the direct effects of $x_{1}$ and $x_{2}$, and the third term is a first order interaction effect. The fourth term is the variance of the covariance product about the covariance parameter, is necessarily positive and is neutral for purposes of interpretation. The last two terms are higher-order interaction effects (Burt and Finley 1968).

Dividing expression (4) by the sum of the first two terms leads to a standardized form of the first three terms: 


$$
\frac{\mu_{2}^{2} \operatorname{Var}\left(x_{1}\right)+\mu_{1}^{2} \operatorname{Var}\left(x_{2}\right)+2 \mu_{1} \mu_{2} \operatorname{Cov}\left(x_{1}, x_{2}\right)}{\mu_{2}^{2} \operatorname{Var}\left(x_{1}\right)+\mu_{1}^{2} \operatorname{Var}\left(x_{2}\right)}=p_{1}+p_{2}+p_{12}
$$

Both $p_{1}$ and $p_{2}$ are positive and sum to unity while $p_{12}$ can be of either sign.

Because we focus on the whole farm income and the role of DP, it is more suitable to applying the variance decomposition that relies on additive components. This leads to the known formula of the variance of a sum:

$$
\operatorname{Var}(y)=\operatorname{Var}\left(x_{1}\right)+\operatorname{Var}\left(x_{2}\right)+2 \operatorname{Cov}\left(x_{1}, x_{2}\right)
$$

Applying expression (6) to the variance of FI as expressed in (1) leads to (Kimura et al. 2010):

$$
\begin{aligned}
\operatorname{Var}(F I) & =\operatorname{Var}(R E V)+\operatorname{Var}(D P)+\operatorname{Var}(E C) \\
& +2 \operatorname{Cov}(R E V, D P)-2 \operatorname{Cov}(R E V, E C)-2 \operatorname{Cov}(D P, E C)
\end{aligned}
$$

Dividing expression (7) by the sum of the first three terms would give a standardized form for interpretation:

$$
\begin{aligned}
& \frac{\operatorname{Var}(R E V)+\operatorname{ar}(D P)+\operatorname{Var}(E C)+2 \operatorname{Cov}(R E V, D P)-2 \operatorname{Cov}(R E V, E C)-2 \operatorname{Cov}(D P, E C)}{\operatorname{Var}(R E V)+\operatorname{Var}(D P)+\operatorname{Var}(E C)}= \\
& =p_{1}+p_{2}+p_{3}+p_{12}-p_{13}-p_{23}
\end{aligned}
$$

where $p_{1}, p_{2}$, and $p_{3}$ are the direct effects while $p_{12}, p_{13}$ and $p_{23}$ are the covariance effects. The three direct effects sum to unity and an increase of the variance of anyone of these increases the variability of FI. A negative (positive) covariance between two components show that they move in the opposite (same) direction over time (El Benni and Finger 2013). This allows for a reduction (increase) of the variability of FI. The results of the income decomposition analysis is expected to provide insights on the income stabilising role of DP.

The role of DP on income stabilisation is also analysed by comparing the coefficient of variation calculated on FI with and without DP (i.e. MI). While very useful for comparisons, coefficient of variations are not suitable when the mean values of the variable takes values that are close to zero or are negative. In the considered sample, this is never the case of FI but the same cannot be said for MI: while it always sufficiently differs from zero, in some farms MI takes a negative value. In order to cope with this problem, the comparison of variability of FI and MI is developed only on those farms that have a non-negative mean value of MI. This restricts such analysis on a constant sub-sample of 2191 farms (i.e. $91.2 \%$ of the whole sample).

Pearson's correlations between DP and MI have been calculated on the 10 year data of each farm. Only average data for the whole sample and each group are shown in the tables. Correlation analysis has also been used to assess whether DP are targeted to stabilise the income of farms facing larger income variability levels. This is done by calculating the Pearson's correlation between the relative importance of DP (PSE) and the level of CV of MI.

Whenever considered important and possible, differences among farm groups have been statistically tested. In the case of $\mathrm{CV}$, the presence of some outliers has been detected. Thus, tests on CV levels have been developed by means of both Kruskal-Wallis and Wilcoxon rank-sum test (Kruskal and Wallis 1952; Mann and Whitney 1947) because less affected by the presence of outliers. 


\section{Results and discussion}

\section{Support provided by direct payments}

The level of support provided by DP to the considered farms is relevant: on average DP account for around $13.2 \%$ of total farm receipts (PSE) and $42.6 \%$ of farm income (DP/ FI) (Table 1). However, there are relevant differences within the farm sample. Around $10 \%$ of the farms did not receive DP in the considered 10-year period and most of these belong to the group of Specialist horticulture farms (Table 1).

On the contrary, DP account for an extraordinary high share of income in Specialist field crop, in Mixed livestock and crops-livestock, Specialist grazing livestock and Mixed cropping farms (Table 1). ${ }^{3}$ The relative importance of DP is higher in small farms than in medium and large farms. The assessed overall relative importance of DP suggests that the income of many farms strongly relies on the benefits coming from this policy.

Because CAP policy has changed in terms of both DP policy and price support during the considered period and this should be kept in mind when assessing the obtained results. ${ }^{4}$ However, the level of price support has been drastically reduced during the period in these products. In some of these sectors, such as dairy, this has been compensated by an increase of DP level.

\section{Variability of farm income over time}

Variability of farm income over time is high. On the whole sample, the median coefficient of variation of farm income (CV of FI) is 0.64 (Table 2). This suggests that variability of FI in on average not negligible and supports the hypothesis that risk adverse farmers should be interested in using risk management strategies and tools Differences

Table 2 Variability of farm income over time within the considered groups and the whole $\mathbf{s}$ ub-sample of farms with positive market income. Median of the coefficients of variation of farm income

\begin{tabular}{|c|c|c|c|c|c|}
\hline & & \multirow{2}{*}{\multicolumn{3}{|c|}{$\begin{array}{l}\text { CV(FI) } \\
\text { Median }^{d}\end{array}$}} & \multirow{2}{*}{$\frac{C V(F I)}{\text { Median }^{d}}$} \\
\hline & & & & & \\
\hline Types of farming (TF): & TF & & Economic size (ESU): & & \\
\hline Specialist field crops & 1 & $0.666 \mathrm{ab}$ & Small (Classes 1, 2, 3) & & $0.734 \mathrm{a}$ \\
\hline Specialist horticulture & 2 & $0.604 \mathrm{bcd}$ & Medium (Classes 4, 5, 6) & & $0.606 \mathrm{~b}$ \\
\hline Specialist permanent crops & 3 & 0.659 a b & Large (Classes 7, 8) & & $0.619 \mathrm{~b}$ \\
\hline Specialist grazing livestock & 4 & $0.576 \mathrm{~cd}$ & PSE level: & & \\
\hline Specialist granivore & 5 & $0.725 \mathrm{ab}$ & No DP & 0 & $0.599 \mathrm{bc}$ \\
\hline Mixed cropping & 6 & $0.710 \mathrm{ab}$ & Low & $1 s t$ & $0.667 \mathrm{a} b$ \\
\hline $\begin{array}{l}\text { Mixed livestock and Mixed } \\
\text { crops-livestock }\end{array}$ & 7 & 0.658 a b c & Low-Medium & $2 n d$ & $0.629 a b c$ \\
\hline & & & Medium-High & $3 r d$ & $0.661 \mathrm{ab}$ \\
\hline Total sample & & 0.636 & High & 4th & $0.617 \mathrm{a} \mathrm{b} c$ \\
\hline
\end{tabular}

Source: Own elaborations on a constant sample of the whole Italian FADN farms, years 2003-2012

${ }^{\mathrm{d} D i f f e r e n c e s ~ b e t w e e n ~ g r o u p s ~ s t a t i s t i c a l l y ~ s i g n i f i c a n t ~ a t ~} 5 \%$ confidence interval according to Wilcoxon rank-sum test 
among farm groups in terms of income variability are limited and statistically significant only in a few cases (Table 2).

Variability is clearly higher than in the whole sample in specialist granivore and mixed cropping farms, while lower in specialist grazing livestock farms. The high variability of specialised granivore farms is consistent with the findings of Vrolijk and Poppe (2008) and can be explained by the nature of these farms: high specialisation and a limited importance of DP. Similarly, the low level of income variability of specialist grazing farms is consistent with the findings of previous analysis (Vrolijk and Poppe 2008) (Table 2). Variability is also higher in small farms (Median CV is 0.73 ) than in medium and large farms as also reported by Vrolijk and Poppe (2008).

On the contrary, there are only very limited differences among farms with different PSE levels. This does not allow to identify a link between PSE level and variability of farm income because it is not possible to highlight a positive or negative correlation among these two parameters. This issue has been explored by mean of the variance decomposition by income sources that allows to identify the income components that most contribute to the overall variability of farm income.

\section{Income components that most contribute to income variability}

Variance decomposition is used to identify the income components that most contribute to income variability. Results show that most of the variance is due to revenues (65 \%) and costs for external factors (around $30 \%$ ) (Table 3). On the contrary, DP account only for the remaining part of the variability (i.e. $5 \%$ ) even if, as already said, DP account for around $40 \%$ of the FI, on average.

The relatively high variability of farm revenues can be due to the variability of both price and production levels. Indeed, during the considered period there has been a not negligible variability of farm product prices (Fig. 1, in the Appendix). Farm product prices have shown a very relevant spike in 2008 followed by relatively low levels in the years 2009 and 2010. Such evolution has been experienced by both livestock and crop products, but the 2008 spike has been particular strong in the crop products caused by a strong increase of the prices of cereals (Fig. 1, Appendix). However, the effect of such price shocks on farm income can strongly vary in the farms according to both their production pattern and level of diversification, provided that most of the considered farms are multiproduct farms.

Variability of farm costs is also a factor explaining a not negligible share of the FI variability (i.e. around $30 \%$ ) (Table 3). Such variability has been also caused by the relevant variability of the prices of the inputs purchased by farmers and experienced during the considered period (Fig. 2, in the Appendix). A relevant price spike has been experienced in 2004 and, as for the product case, 2008. This can probably explain part of the variability of external costs faced by the considered farms during the study period. However, it is worth noticing that in 2008 both product prices and input prices have experienced extraordinary high levels. This means that the high input costs experienced in that year have reduced the increase of FI due to the high level of farm revenues caused by high product prices.

So far the discussion has focused on the direct effects of the three considered income components only. However, it is important to also account for the indirect effects, linked to the correlation between these income components. Overall, indirect effects provide a limited contribution to the total variability being negligible except for the covariance effect 
Table 3 Sources of variability of farm income in the whole sample and in the sub-groups of farms

\begin{tabular}{|c|c|c|c|c|c|c|c|c|c|c|}
\hline & & \multicolumn{6}{|c|}{ Variance decomposition $^{a}$} & \multirow{2}{*}{\multicolumn{3}{|c|}{$\begin{array}{l}\text { Relative } \\
\text { importance of } \\
\text { income sources }\end{array}$}} \\
\hline & & \multicolumn{3}{|c|}{ Direct effects } & \multicolumn{3}{|c|}{ Indirect effects } & & & \\
\hline & & $\mathrm{p}_{1}$ & $p_{2}$ & $p_{3}$ & $\mathrm{p}_{12}$ & $p_{13}$ & $\mathrm{p}_{23}$ & $\mathrm{REV} / \mathrm{FI}$ & $\mathrm{DP} / \mathrm{FI}$ & $\mathrm{EC} / \mathrm{FI}$ \\
\hline Types of farming (TF): & TF & Mean & & & & & & Mean & & \\
\hline Specialist field crops & 1 & 0.617 & 0.082 & 0.301 & -0.026 & 0.294 & 0.028 & 2.84 & 0.81 & 2.65 \\
\hline Specialist horticulture & 2 & 0.699 & 0.006 & 0.296 & -0.005 & 0.321 & 0.004 & 2.81 & 0.02 & 1.83 \\
\hline Specialist permanent crops & 3 & 0.688 & 0.045 & 0.267 & -0.016 & 0.250 & 0.011 & 2.68 & 0.25 & 1.94 \\
\hline Specialist grazing livestock & 4 & 0.601 & 0.062 & 0.337 & -0.035 & 0.263 & 0.005 & 2.29 & 0.46 & 1.74 \\
\hline Specialist granivore & 5 & 0.599 & 0.010 & 0.392 & -0.006 & 0.562 & 0.008 & 4.07 & 0.19 & 3.26 \\
\hline Mixed cropping & 6 & 0.640 & 0.056 & 0.304 & -0.027 & 0.293 & 0.028 & 3.08 & 0.45 & 2.52 \\
\hline $\begin{array}{l}\text { Mixed livestock and Mixed } \\
\text { crops-livestock }\end{array}$ & 7 & 0.605 & 0.055 & 0.340 & -0.039 & 0.302 & 0.022 & 3.11 & 0.61 & 2.71 \\
\hline \multicolumn{11}{|l|}{ Economic size (ESU): } \\
\hline Small (Classes 1, 2, 3) & & 0.648 & 0.047 & 0.305 & -0.022 & 0.269 & 0.019 & 3.04 & 0.56 & 2.61 \\
\hline Medium (Classes 4, 5, 6) & & 0.647 & 0.057 & 0.296 & -0.024 & 0.282 & 0.014 & 2.58 & 0.38 & 1.96 \\
\hline Large (Classes 7, 8) & & 0.583 & 0.038 & 0.379 & 0.009 & 0.486 & -0.003 & 3.32 & 0.31 & 2.63 \\
\hline \multicolumn{11}{|l|}{ PSE level: } \\
\hline No DP & 0 & 0.698 & 0.000 & 0.302 & 0.000 & 0.328 & 0.000 & 2.83 & - & 1.83 \\
\hline Low & $1 s t$ & 0.718 & 0.007 & 0.275 & -0.002 & 0.289 & 0.004 & 2.97 & 0.07 & 2.04 \\
\hline Low-Medium & 2nd & 0.664 & 0.034 & 0.302 & -0.025 & 0.270 & 0.006 & 2.99 & 0.28 & 2.27 \\
\hline Medium-High & $3 r d$ & 0.625 & 0.055 & 0.319 & -0.014 & 0.321 & 0.015 & 2.81 & 0.56 & 2.36 \\
\hline High & 4 th & 0.546 & 0.139 & 0.315 & -0.059 & 0.251 & 0.040 & 2.19 & 1.00 & 2.19 \\
\hline Total sample & & 0.645 & 0.053 & 0.303 & -0.022 & 0.288 & 0.015 & 2.75 & 0.43 & 2.18 \\
\hline
\end{tabular}

Variance decomposition and relative importance of the three considered income sources

Source: Own elaborations on a constant sample of the whole Italian FADN farms, years 2003-2012

${ }^{a}$ Subscripts 1, 2 and 3 refer to revenues, direct payments and external costs, respectively

among revenues and external costs. Indeed, covariance effect between revenues and DP is negative suggesting that DP could play a scarce but countercyclical role in comparison to fluctuations of revenues over time. Finally, a positive but small indirect effect between DP and external costs exists in the whole sample and in several types of farming suggesting that increases of DP are associated with relatively high levels of external costs.

While the data referring to the whole sample provide an overall picture of the sources of income variability, it is important to highlight differences among types of farming. Direct effect of revenues is higher than the average value in horticulture and permanent crops while it is lower in granivore and mixed crop and mixed crop-livestock farms (Table 3).

The relative contribution of DP to total variability is way higher than the mean in specialist field crops farms. These results are coherent with the relative importance of DP (DP/FI) in these types of farming. The contribution of external costs to the direct effects doesn't change significantly among different types of farming, except for specialist granivore, in which external costs account for a large share of the direct effects. This is coherent with the relative importance of external costs, that is the highest in specialist granivore farms. Differences among farms belonging to different economic sizes and PSE levels can be generally explained by differences in terms of the relative importance of the three income sources. In particular, the relative contribution of DP to income variability increases from the lowest to the highest PSE quartile. However, because such 
farms have an higher share of income variability coming from revenues, it may also support the hypothesis that farmers with high level of DP are more willing to take risk from agricultural production (El Benni et al. 2012).

\section{How DP stabilise farm income}

First of all, DP stabilise farm income because is an income component that is less variable than the other components remaining part of the income, i.e. Market Income (MI) (Table 4).

On average, the variability of FI is around $30 \%$ lower that the variability of MI on average (Table 4). This is also the case in almost all considered types of farming even if the stabilising effect tends to be higher in those groups of farms where DP contribute the most to farm income (Table 4). This general results is confirmed by data referring to farms grouped by economic size and level of PSE (Table 4). The income stabilising role of DP increases moving from the first to the higher quartiles of PSE. In the farms on the highest quartile the CV of FI is around $64 \%$ lower than that of MI. Moreover, differences between $\mathrm{CV}(\mathrm{MI})$ and $\mathrm{CV}(\mathrm{FI})$ are almost always statistical significant at $1 \%$ (Table 4). These results suggest that the extent of the stabilising role of DP increases as

Table 4 Income stabilising effect of direct payments

\begin{tabular}{|c|c|c|c|c|c|c|c|c|}
\hline & & \multirow[t]{3}{*}{$\begin{array}{l}\text { Sample size } \\
\text { number }\end{array}$} & \multicolumn{2}{|c|}{ Importance of DP: } & \multicolumn{3}{|c|}{$\begin{array}{l}\text { Coefficient of } \\
\text { variation of }\end{array}$} & \multirow{2}{*}{$\begin{array}{l}\text { Difference between } \\
\text { CV(MI) and CV(FI) }\end{array}$} \\
\hline & & & $\overline{P S E^{a}}$ & $\mathrm{DP} / \mathrm{FI}$ & $\mathrm{FI}$ & $\mathrm{Ml}$ & $\mathrm{DP}$ & \\
\hline & & & \multicolumn{2}{|l|}{ Mean } & \multicolumn{3}{|c|}{ Median } & Var. $^{\text {b }}$ \\
\hline Types of farming (TF): & TF & & & & & & & \\
\hline Specialist field crops & 1 & 443 & $19.9 \%$ & $49.4 \%$ & 0.608 & 1.287 & 0.304 & $-52.8 \% * * *$ \\
\hline Specialist horticulture & 2 & 276 & $0.8 \%$ & $2.0 \%$ & 0.604 & 0.612 & 1.823 & $-1.3 \%$ \\
\hline Specialist permanent crops & 3 & 689 & $7.7 \%$ & $19.7 \%$ & 0.646 & 0.774 & 0.699 & $-16.5 \% * * *$ \\
\hline Specialist grazing livestock & 4 & 467 & $15.1 \%$ & $35.5 \%$ & 0.567 & 0.861 & 0.361 & $-34.2 \% * * *$ \\
\hline Specialist granivore & 5 & 82 & $5.7 \%$ & $13.2 \%$ & 0.715 & 0.900 & 0.352 & $-20.6 \% * * *$ \\
\hline Mixed cropping & 6 & 147 & $12.2 \%$ & $31.9 \%$ & 0.690 & 0.952 & 0.474 & $-27.5 \% * *$ \\
\hline $\begin{array}{l}\text { Mixed livestock and Mixed } \\
\text { crops-livestock }\end{array}$ & 7 & 87 & $16.2 \%$ & $44.0 \%$ & 0.583 & 1.207 & 0.281 & $-51.7 \% * * *$ \\
\hline \multicolumn{9}{|l|}{ Economic size (ESU): } \\
\hline Small (Classes 1, 2, 3) & & 603 & $12.5 \%$ & $33.3 \%$ & 0.690 & 1.046 & 0.422 & $-34.1 \% * * *$ \\
\hline Medium (Classes 4, 5, 6) & & 1484 & $11.2 \%$ & $26.9 \%$ & 0.592 & 0.819 & 0.445 & $-27.7 \% * * *$ \\
\hline Large (Classes 7, 8) & & 104 & $8.2 \%$ & $20.4 \%$ & 0.612 & 0.790 & 0.412 & $-22.5 \% * *$ \\
\hline \multicolumn{9}{|l|}{ PSE level: } \\
\hline No DP & 0 & 247 & $0.0 \%$ & $0.0 \%$ & 0.599 & 0.599 & 0.000 & $0.0 \%$ \\
\hline Low & $1 \mathrm{st}$ & 538 & $2.0 \%$ & $5.6 \%$ & 0.665 & 0.687 & 1.068 & $-3.2 \%$ \\
\hline Low-Medium & 2nd & 523 & $8.0 \%$ & $22.1 \%$ & 0.615 & 0.756 & 0.444 & $-18.6 \% * * *$ \\
\hline Medium-High & $3 r d$ & 500 & $16.3 \%$ & $44.0 \%$ & 0.632 & 1.107 & 0.334 & $-43.0 \% * * *$ \\
\hline High & 4 th & 383 & $30.4 \%$ & $66.7 \%$ & 0.546 & 1.506 & 0.296 & $-63.8 \% * * *$ \\
\hline Total sub-sample & & 2191 & $11.4 \%$ & $28.4 \%$ & 0.615 & 0.871 & 0.438 & $-29.4 \% * * *$ \\
\hline
\end{tabular}

Variability of farm income (FI), market income (MI = FI-DP) and direct payments (DP). Median of the coefficients of variation (CV) of $\mathrm{Fl}, \mathrm{Ml}$ and $\mathrm{DP}$. Difference between variability of $\mathrm{Ml}$ and of $\mathrm{Fl}$. Whole sub-sample and considered groups ${ }^{a} \mathrm{PSE}=\mathrm{DP} /(\mathrm{REV}+\mathrm{DP}) .{ }^{\mathrm{b}}$ Calculated as: $(\mathrm{CV}(\mathrm{MI})-\mathrm{CV}(\mathrm{FI})) / \mathrm{CV}(\mathrm{FI})$. Significant difference at $1 \%\left({ }^{* * *}\right), 5 \%\left({ }^{* *}\right)$.

Source: Own elaborations on the sub-sample of farms with Ml greater than zero. Years 2003-2012 
the relative level of DP increases and confirm that farms enjoying higher levels of DP can afford to cope with high level of market income variability better than other farms (El Benni et al. 2012).

DP are also characterised by some variability: the median value of the coefficients of variation of DP calculated on all farms of the sample is around 0.44 although there are relevant differences among the considered types of farming. Excluding specialist horticulture farms (where DP are often zero or negligible), CVs of DP vary from 0.70 in specialist permanent crops to 0.28 in mixed livestock and mixed crops-livestock farms (Table 4).

Because of the variability of DP is not negligible, it seems important to explore whether DP play a countercyclical role against fluctuation of market income over time. This is because, if the evolution of DP over the considered decade is negatively correlated with the evolution of MI, this increases the effectiveness of the income stabilisation role DP play. Empirical results suggest that DP play only a limited countercyclical role against fluctuations of MI over time. This is shown by the fact that the correlation between the 10-year series of MI and DP calculated in each farm is negative but very small on the whole subsample and in most of the considered farm groups (Table 5). Because of this, it is possible to say that the same amount of financial resources used for DP could play a way stronger income stabilising effect in the (very theoretical) case in which DP levels were designed in a way to be negatively correlated with the evolution of MI levels over time such as a typical countercyclical payment.

A final issue is whether DP are specifically targeted to stabilise the income of those farms facing large income variability levels or not. This issue is relevant from a policy point of view because a good targeting should result in the enhancement of the efficiency of the policy against the objective of the stabilisation of FI. ${ }^{5}$ Empirical results support the hypothesis that DP are not well targeted because the correlation between the variability of MI and the relative level of DP (PSE) is very low on average and in many of the considered types of farming. The same is true for farms within different size and relative PSE groups, with the highest level of correlation (0.356) observed in large farms (Table 5).

\section{Conclusions}

The analysis has studied the role of CAP direct payments (DP) in stabilising farm income using individual farm data for a decade. First, the extent of farm income variability over time has been assessed. Second, the contribution of the three main income components (Revenues, DP and costs of external factors) to the variability of farm income has been analysed. This has allowed to establish that DP play an income stabilising effect. Third, the analysis has explored how DP reduce farm income variability. Addressing these three topics provided pieces of information that could be used to design a DP policy that better pursues farm income stabilisation objectives.

The analysis has confirmed the results of previous studies stating that the variability over time of farm income is high even if some limited differences among farm groups exist. While the median coefficients of variation of farm income of the whole sample is higher than 0.6, the variability is relatively lower only in specialist grazing farms than in other types of farming. Coherently with results of previous studies, small farms face higher level of income variability than larger size farms. Finally, farms that do not benefit at all from DP have a relatively lower level of variability of their income. The assessed extent of income variability seems high enough to justify the attention paid 
Table 5 Correlation between MI and DP and between the coefficient of variation of MI and of DP

\begin{tabular}{|c|c|c|c|c|}
\hline & & \multirow{2}{*}{$\begin{array}{l}\text { Sample size } \\
\text { number }\end{array}$} & \multicolumn{2}{|c|}{ Correlation ${ }^{a}$ between: } \\
\hline & & & MI and DP (mean) & $\mathrm{CV}(\mathrm{MI})$ and $\mathrm{PSE}$ \\
\hline Types of farming (TF): & TF & & & \\
\hline Specialist field crops & 1 & 443 & $-0.094 * * *$ & 0.016 \\
\hline Specialist horticulture & 2 & 276 & -0.024 & 0.264 \\
\hline Specialist permanent Crops & 3 & 689 & $-0.033 *$ & 0.180 \\
\hline Specialist grazing livestock & 4 & 467 & $-0.036 *$ & 0.109 \\
\hline Specialist granivore & 5 & 82 & -0.043 & 0.254 \\
\hline Mixed cropping & 6 & 147 & $-0.086^{* *}$ & 0.296 \\
\hline Mixed livestock and Mixed crops-livestock & 7 & 87 & -0.048 & 0.023 \\
\hline \multicolumn{5}{|l|}{ Economic size (ESU): } \\
\hline Small (Classes 1, 2, 3) & & 603 & $-0.086 * * *$ & 0.036 \\
\hline Medium (Classes 4, 5, 6) & & 1484 & $-0.045^{* * *}$ & 0.052 \\
\hline Large (Classes 7, 8) & & 104 & 0.062 & 0.356 \\
\hline \multicolumn{5}{|l|}{ PSE level: } \\
\hline No DP & 0 & 247 & / & / \\
\hline Low & $1 s t$ & 538 & 0.002 & 0.057 \\
\hline Low-Medium & 2nd & 523 & $-0.059 * * *$ & 0.017 \\
\hline Medium-High & $3 r d$ & 500 & $-0.061 * * *$ & 0.061 \\
\hline High & 4th & 383 & $-0.104^{* * *}$ & 0.064 \\
\hline Total sub-sample & & 2191 & $-0.051 * * *$ & 0.045 \\
\hline
\end{tabular}

Farms with non-negative MI. Whole sub-sample and considered groups

Source: Own elaborations on a constant sample of the Italian FADN farms, years 2003-2012

${ }^{a}$ Significantly different from zero at $1 \%\left({ }^{* *}\right), 5 \%\left({ }^{* *}\right)$ and $10 \%\left({ }^{*}\right)$. ${ }^{\mathrm{P} P S E}=\mathrm{DP} /(\mathrm{REV}+\mathrm{DP})$

during the recent reform of the CAP and that has driven to establishing policy measures to help farmers to manage farm risk.

The analysis on the sources of income variability has shown that, as expected, most of the variability comes from revenues, although a not negligible contribution to such variability also comes from farm costs. Because of this, it could be suggested to focus on policy instruments aimed at reducing revenue variability. However, before doing so, it is needed to take into account that DP already contribute to stabilise income. This is because DP contribute to around $5 \%$ of the direct effects of income variability but accounts for more than $40 \%$ of farm income, on average.

Finally, the analysis has provided evidences on how DP stabilise income. First, this is mainly because DP have a lower (but not negligible) level of variability than the remaining part of the income: the coefficient of variation of DP is around half of the one referring to market income (i.e. farm income net of DP) and around $2 / 3$ of that of farm income. Second, DP play a limited countervailing role against fluctuations of market income over time provided that the correlation between DP and market income is negative. However, the level of such correlation is very limited.

These findings support the idea that DP stabilise farm income even if the extent of such effect is high only in those farms benefiting from a relatively large amount of DP. This has relevant policy implications provided that the distribution of DP is going to drastically change because of the recent reform of the CAP is expected to shift resources from farms with relatively high levels of DP to those with relatively low levels 
of DP. This implies that, ceteris paribus, farms that will face the stronger reduction of DP levels will also experience an increase of their income variability. Consequently, these farms may need to manage farm risk better and more extensively than in the past. However, because the analysis has been developed on the past DP policy, a better assessment of the reform will be only possible when data regarding the new distribution of DP will become available.

Overall, the results of the analysis could feed the debate around possible future developments of the DP policy. In particular, such results support the idea that, in case of exceptional negative conditions, the amount of DP could be increased in order to balance the resulting market income decrease. However, at least in the short run, the scope for changing the DP policy are very limited because of several reasons. First, a reform has been agreed recently and has begun to be implemented just in 2015. Second, allowing DP level to change over time to compensate for changes in market income makes CAP spending to vary yearly, a situation that is not compatible with the current CAP financial rules. Finally, there is a lack of detailed enough data regarding the income condition of individual farms in order to calibrate DP level according to the income level of the farms.

\section{Endnotes}

${ }^{1}$ The Finger-Kreinin index has been originally developed to compare the structure of the export of products of two countries. It sums the shares of all products considering, for each product, the minimum value between the two series. Thus, it assumes a value of $100 \%$ in the case of complete similarity, while it tends to zero as long as similarity declines.

${ }^{2}$ The considered period is characterized by a change in the Italian FADN methodology occurred in 2008, due to the introduction of a new software named GAIA. Anyway, this discontinuity in the series does not strongly affect the extent of the economic figures. In fact, the analysis of the evolution of the relative levels of farm income (the main economic indicator used in the analysis) has not shown a clear discontinuity between 2007 and 2008. In particular, of the 7 considered types of farms, 4 have shown an increase, while the remaining types have experienced a reduction of income level (Table 9 in the Appendix). Furthermore, other Authors have used the full series (i.e. before and after the change) for analysis of farm income without reporting relevant discontinuities in the data series (Henke and Salvioni 2013).

${ }^{3}$ Differences in the level of support provided by DP among types of farming are in some cases due to the fact that some productions have been supported by means of price policies other than by DP policies.

${ }^{4}$ The analysis of the level of support provided by DP to farms belonging to the considered types of farming has not provided evidences of a relevant structural change during the study period (Table 10 in the Appendix). Support provided by price policy has been relatively high only in some specific sectors and at the beginning of the considered decade. According to OECD estimates of the Market Price Support for the whole EU (OECD), products such as milk, beef and, to a way lower extent, mais have been heavily supported at the beginning of the study period (Table 11, Appendix).

${ }^{5}$ It is important to underline that DP are indeed aimed at increasing the (average) level of income, not just at reducing its variability. Thus, the policy should be evaluated against both objectives. 


\section{Appendix}

Table 6 Comparison of the distributions of the farms in the considered sub-sample and in the whole FADN sample within geographical areas and altimetry zones

\begin{tabular}{|c|c|c|c|c|c|}
\hline & \multicolumn{2}{|l|}{ Sub-sample } & \multicolumn{2}{|c|}{ Whole sample (2012) } & \multirow[t]{2}{*}{ Similarity ${ }^{\mathrm{a}}$} \\
\hline & N. of farms & $\%$ & N. of farms & $\%$ & \\
\hline Geographical areas: & & & & & $90 \%$ \\
\hline Center & 343 & $14 \%$ & 2098 & $19 \%$ & \\
\hline Islands & 171 & $7 \%$ & 1172 & $10 \%$ & \\
\hline South & 626 & $26 \%$ & 2903 & $26 \%$ & \\
\hline Northwest & 763 & $32 \%$ & 2423 & $22 \%$ & \\
\hline Northest & 499 & $21 \%$ & 2593 & $23 \%$ & \\
\hline Whole country & 2402 & $100 \%$ & 11,189 & $100 \%$ & \\
\hline Altimetry zones: & & & & & $98 \%$ \\
\hline Hilly & 1130 & $47 \%$ & 5072 & $45 \%$ & \\
\hline Mountain & 478 & $20 \%$ & 2326 & $21 \%$ & \\
\hline Plan & 794 & $33 \%$ & 3791 & $34 \%$ & \\
\hline Whole country & 2402 & $100 \%$ & 11,189 & $100 \%$ & \\
\hline
\end{tabular}

Source: own elaboration on Italian FADN data

${ }^{\mathrm{a}}$ Finger and Kreinin (1979) similarity index. $100 \%$ means complete similarity

Table 7 Comparison of the distributions of the farms in the considered sub-sample and in the whole FADN sample within geographical areas and altimetry zones

\begin{tabular}{|c|c|c|c|c|c|c|}
\hline & & \multicolumn{2}{|l|}{ Sub-sample } & \multicolumn{2}{|c|}{ Whole sample (2012) } & \multirow{2}{*}{$\begin{array}{l}\text { Similarity } \\
93 \%\end{array}$} \\
\hline & & N. of farms & $\%$ & N. of farms & $\%$ & \\
\hline Types of farming (TF) & Code & & & & & \\
\hline Specialist field crops & 1 & 571 & $24 \%$ & 3007 & $27 \%$ & \\
\hline Specialist horticulture & 2 & 276 & $11 \%$ & 824 & $7 \%$ & \\
\hline Specialist permanent crops & 3 & 715 & $30 \%$ & 3073 & $27 \%$ & \\
\hline Specialist grazing livestock & 4 & 492 & $20 \%$ & 2504 & $22 \%$ & \\
\hline Specialist granivore & 5 & 84 & $3 \%$ & 524 & $5 \%$ & \\
\hline Mixed cropping & 6 & 161 & $7 \%$ & 691 & $6 \%$ & \\
\hline Mixed livestock and Mixed crops-livestock & 7 & 103 & $4 \%$ & 566 & $5 \%$ & \\
\hline Economic size (ESU classes) & & & & & & $98 \%$ \\
\hline Small (Classes 1, 2 and 3) & & 697 & $29 \%$ & 3100 & $28 \%$ & \\
\hline Medium (Classes 4, 5, 6) & & 1595 & $66 \%$ & 7311 & $65 \%$ & \\
\hline Large (Classes 7 and 8) & & 110 & $5 \%$ & 778 & $7 \%$ & \\
\hline Whole country & & 2402 & $100 \%$ & 11189 & $100 \%$ & \\
\hline
\end{tabular}

Source: own elaboration on Italian FADN data

${ }^{a}$ Finger and Kreinin (1979) similarity index. $100 \%$ means complete similarity 
Table 8 Analysis of trends in farm income (OLS linear trends)

\begin{tabular}{|c|c|c|c|c|c|c|c|c|}
\hline & & \multicolumn{7}{|c|}{ Trends in farm income ${ }^{a}$} \\
\hline & & \multicolumn{2}{|c|}{ Strictly positive } & \multicolumn{2}{|c|}{ Negative } & \multicolumn{2}{|c|}{ Subtotal } & \multirow[b]{2}{*}{ Total } \\
\hline & & Farms & $\%$ & Farms & $\%$ & Farms & $\%$ & \\
\hline Types of farming (TF): & TF & & & & & & & \\
\hline Specialist field crops & 1 & 42 & $72.4 \%$ & 16 & $27.6 \%$ & 58 & $10.2 \%$ & 571 \\
\hline Specialist horticulture & 2 & 35 & $81.4 \%$ & 8 & $18.6 \%$ & 43 & $15.6 \%$ & 276 \\
\hline Specialist permanent crops & 3 & 49 & $79.0 \%$ & 13 & $21.0 \%$ & 62 & $8.7 \%$ & 715 \\
\hline Specialist grazing livestock & 4 & 42 & $56.8 \%$ & 32 & $43.2 \%$ & 74 & $15.0 \%$ & 492 \\
\hline Specialist granivore & 5 & 6 & $60.0 \%$ & 4 & $40.0 \%$ & 10 & $11.9 \%$ & 84 \\
\hline Mixed cropping & 6 & 11 & $100.0 \%$ & 0 & $0.0 \%$ & 11 & $6.8 \%$ & 161 \\
\hline Mixed livestock and Mixed crops-livestock & 7 & 11 & $78.6 \%$ & 3 & $21.4 \%$ & 14 & $13.6 \%$ & 103 \\
\hline Total & & 196 & $72.1 \%$ & 76 & $28 \%$ & 272 & $11 \%$ & 2402 \\
\hline
\end{tabular}

Source: Own elaborations on a constant sample of the Italian FADN farms, years 2003-2012

${ }^{\mathrm{a}} \mathrm{R} 2>0.6$ and trend coefficient significantly different from zero at $5 \%$

Table 9 Evolution of farm income level by type of farming in the analysed period $(2003=100)$

\begin{tabular}{llllllllllll}
\hline & \multicolumn{1}{c}{ Farm income level $(2003=100)$} \\
\cline { 2 - 11 } & & 2003 & 2004 & 2005 & 2006 & 2007 & 2008 & 2009 & 2010 & 2011 & 2012 \\
\hline Types of farming (TF): & TF & & & & & & & & & \\
Specialist field crops & 1 & 100 & 101 & 102 & 99 & 131 & 138 & 124 & 115 & 115 & 113 \\
Specialist horticulture & 2 & 100 & 97 & 96 & 99 & 100 & 108 & 103 & 101 & 95 & 73 \\
Specialist permanent crops & 3 & 100 & 90 & 94 & 92 & 99 & 123 & 99 & 133 & 113 & 113 \\
Specialist grazing livestock & 4 & 100 & 87 & 90 & 109 & 107 & 114 & 104 & 109 & 112 & 105 \\
Specialist granivore & 5 & 100 & 137 & 104 & 79 & 74 & 66 & 88 & 76 & 56 & 74 \\
Mixed cropping & 6 & 100 & 96 & 91 & 98 & 140 & 114 & 123 & 140 & 145 & 128 \\
Mixed livestock and Mixed & 7 & 100 & 93 & 115 & 112 & 154 & 127 & 131 & 113 & 99 & 117 \\
crops-livestock & & & & & & & & & & & \\
Total sample & 100 & 99 & 97 & 98 & 106 & 112 & 105 & 110 & 103 & 101 \\
\hline
\end{tabular}

Source: Own elaborations on a constant sample of the Italian FADN farms, years 2003-2012

Table 10 Evolution of the relative importance of DP (PSE) by types of farming in the analysed period

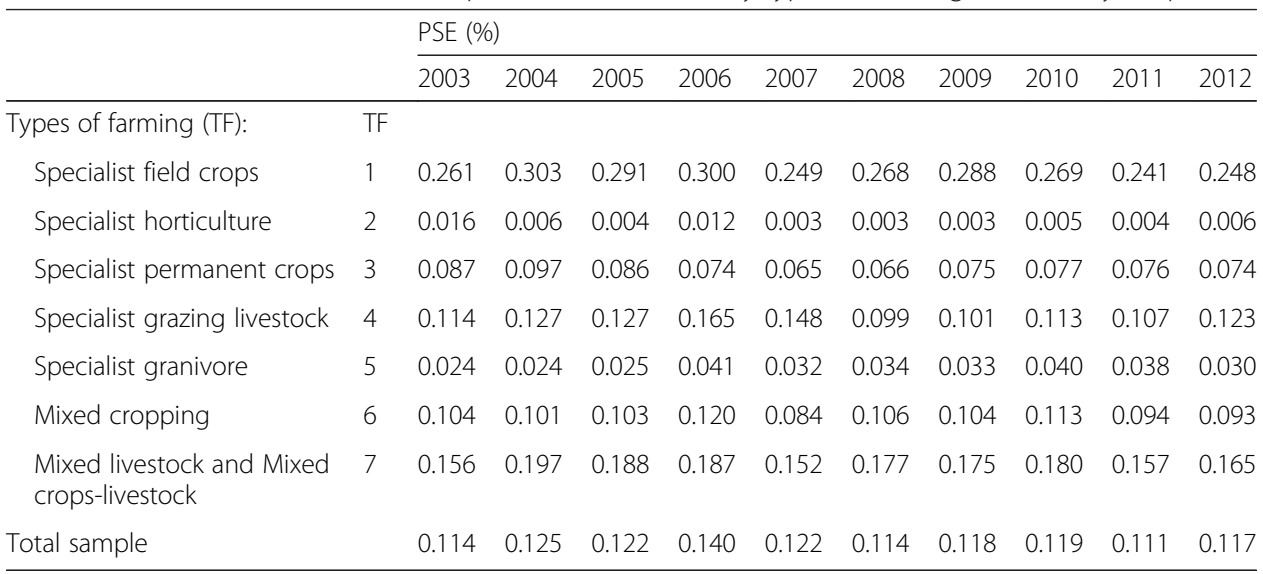

Source: Own elaborations on a constant sample of the Italian FADN farms, years 2003-2012 
Table 11 Evolution of market price support (MPS) in selected products at EU level in the analysed period (MPSNalue of production at farm gate)

\begin{tabular}{|c|c|c|c|c|c|c|c|c|c|c|}
\hline & \multicolumn{10}{|c|}{ MPS/Nalue of production at farm gate (\%) } \\
\hline & 2003 & 2004 & 2005 & 2006 & 2007 & 2008 & 2009 & 2010 & 2011 & 2012 \\
\hline \multicolumn{11}{|l|}{ Selected products: } \\
\hline Common wheat & 0.7 & 0.0 & 0.0 & 0.0 & 0.0 & 0.0 & 0.0 & 0.0 & 0.0 & 0.0 \\
\hline Mais & 19.8 & 10.4 & 14.5 & 10.1 & 23.3 & 0.0 & 0.0 & 0.0 & 0.0 & 0.0 \\
\hline Milk & 44.5 & 38.1 & 25.9 & 18.8 & -0.4 & 9.5 & 0.0 & 0.0 & 0.0 & 0.3 \\
\hline Beef & 44.1 & 43.4 & 47.4 & 46.9 & 43.5 & 28.8 & 32.4 & 11.7 & 9.7 & 28.2 \\
\hline Tomatoes & 2.1 & 0.0 & 0.0 & 0.0 & 7.5 & 9.3 & 0.2 & 6.4 & 3.3 & 2.3 \\
\hline Potatoes & 8.8 & 8.8 & 8.8 & 8.8 & 8.9 & 8.8 & 8.8 & 8.7 & 8.7 & 8.8 \\
\hline
\end{tabular}

Source: Own elaborations on OECD (Producer and Consumer Support Estimates database) 2014

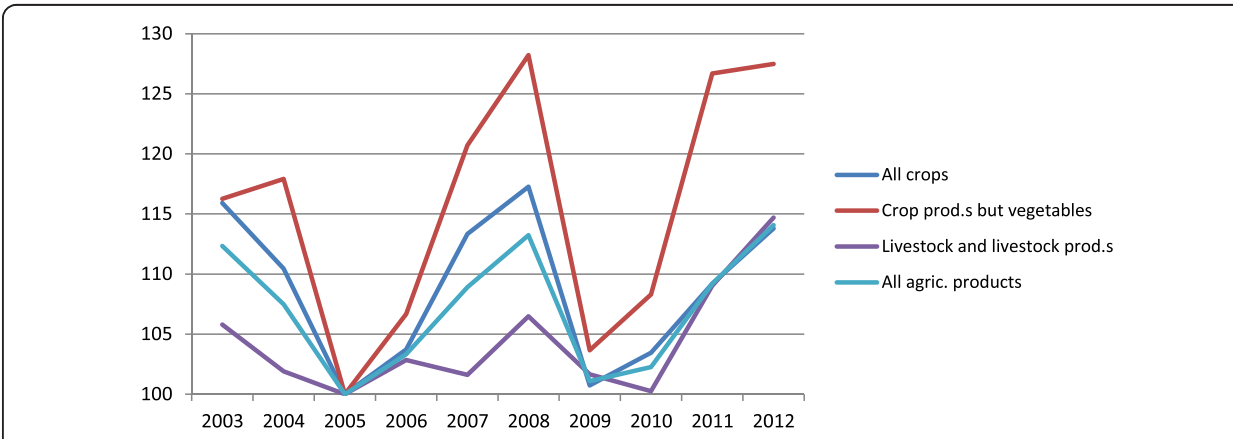

Fig. 1 Evolution of farm product prices in the considered years in Italy. Deflated data. $2005=100$. Source: Own elaborations on ISTAT data

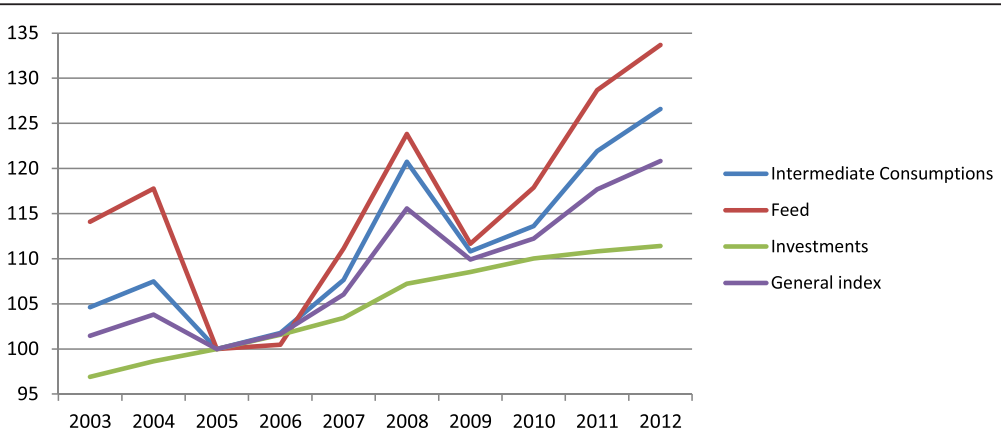

Fig. 2 Evolution of farm input prices in the considered years in Italy. Deflated data. $2005=100$. Source: Own elaborations on ISTAT data 


\section{Abbreviations}

CAP: common agricultural policy; CV: coefficient of variation (standard deviation/mean); DP: direct payments of the CAP; EC: external costs; ESU: economic size units; FI: farm income; MI: market income; PSE: relative importance of DP on farm revenues (DP/(REV + DP)); REV: farm revenues; TF: types of farming.

\section{Competing interests}

The authors declare that they have no competing interests.

\section{Authors' contributions}

SS coordinated the research and has defined, together with AT, the methodology. AT has developed the variance decomposition and drafted the paragraph "Methodology". GD has developed the statistical tests regarding the differences between groups. The other paragraphs have been drafted jointly by the authors. All authors read and approaved the final manuscript.

Received: 8 July 2015 Accepted: 12 February 2016

Published online: 27 February 2016

\section{References}

Agrosynergie (2011) Evaluation of income effects of direct support. Final report., Bruxelles, May. http://ec.europa.eu/ agriculture/eval/reports/income/fulltext_en.pdf. Accessed 30 June 2015

Burt OR, Finley RM (1968) Statistical analysis of identities in random variables. Am J Agric Econ 50(3):734-744

Cafiero C, Capitanio F, Cioffi A, Coppola A (2007). Risk and Crisis Management in the Reformed European Agricultural Policy. Canadian Journal of Agricultural Economics/Revue canadienne d'agroeconomie. 55:419-441

El Benni N, Finger R (2013) Gross revenue risk in Swiss dairy farming. J Dairy Sci 96:936-948

El Benni N, Finger R, Mann S (2012) Effects of agricultural policy reforms and farm characteristics on income risks in Swiss agriculture. Agr Finance Rev 72(3):301-324

Enjolras G, Capitanio F, Aubert M, Adinolfi F (2014) Direct payments, crop insurance and the volatility of farm income. Some evidence in France and Italy. New Medit 1(2014):31-40

European Commission (2010a) Developments in the income situation of the EU agricultural sector. DG Agriculture and Rural development., Bruxelles. http://ec.europa.eu/agriculture/rica/pdf/hc0301_income.pdf. Accessed 30 June 2015

European Commission (2010b) Farm accountancy data network. An A to Z of methodology., http://ec.europa.eu/ agriculture/rica/pdf/site_en.pdf. Accessed 30 June 2015

Finger JM, Kreinin ME (1979) A measure of 'export similarity' and its possible uses. Econ J 89(356):905-912

Hadrich JC (2013) Quantifying the sources of revenue variation in the Northern Great Plains. Agr Finance Rev 73(3):493-506 Henke R, Salvioni C (eds) (2013) I redditi in agricoltura. Processi di diversificazione e politiche di sostegno. INEA, Roma

Kimura S, Antón J, LeThi C (2010) Farm level analysis of risk and risk management strategies and policies: cross country analysis., OECD Food, Agriculture and Fisheries Working Papers, No. 26, OECD Publishing. doi: 10.1787/5kmd6b5rl5kd-en

Kruskal WH, Wallis WA (1952) Use of ranks in one-criterion variance analysis. J Am Stat Assoc 47(260):583-621

Mann HB, Whitney DR (1947) On a test of whether one of two random variables is stochastically larger than the other. Ann Math Stat 18(1):50-60

Meuwissen MPM, van Asseldonk MAPM, Huirne RBM (eds) (2008) Income stabilisation in European agriculture. Wageningen Academic Publishers, Wageningen, The Netherlands

Mishra AK, Sandretto CL (2002) Stability of farm income and role of nonfarm income in U.S. agriculture. Rev Agric Econ 24(1):208-221

Mishra AK, El-Osta HS, Morehart MJ, Johnson JD, Hopkins JW (2002) Income, wealth, and the economic well-being of farm households. In: Agricultural Economic Report No. 812., U.S. Department of Agriculture http://www.ers.usda. gov/media/889418/aer812.pdf. Accessed 30 June 2015

OECD (2009) Managing risk in agriculture. A holistic approach. OECD publication, Paris, http:/www.keepeek.com/Digital-AssetManagement/oecd/agriculture-and-food/managing-risk-in-agriculture_9789264075313-en. Accessed 30 June 2015

OECD (2014) Agricultural policy monitoring and evaluation 2014: OECD Countries. OECD Publishing, Paris, http://www. keepeek.com/Digital-Asset-Management/oecd/agriculture-and-food/agricultural-policy-monitoring-and-evaluation2014_agr_pol-2014-en. Accessed 30 June 2015

OECD (2014) Producer and Consumer Support Estimates database. OECD, Paris. http://www.oecd.org/tad/agriculturalpolicies/producerandconsumersupportestimatesdatabase.htm\#tables. Accessed 30 Sept 2015

Offutt SE, Blandford D (1986) Commodity market instability: empirical techniques for analysis. Resour Pol 12:62-72

Vrolijk HCJ, Poppe KJ (2008) Income variability and income crisis in the European Union. In: Meuwissen MPM, van Asseldonk MAPM, Huirne RBM (eds) Income stabilisation in European agriculture. Wageningen Academic Publishers, Wageningen, The Netherlands, pp 33-54 